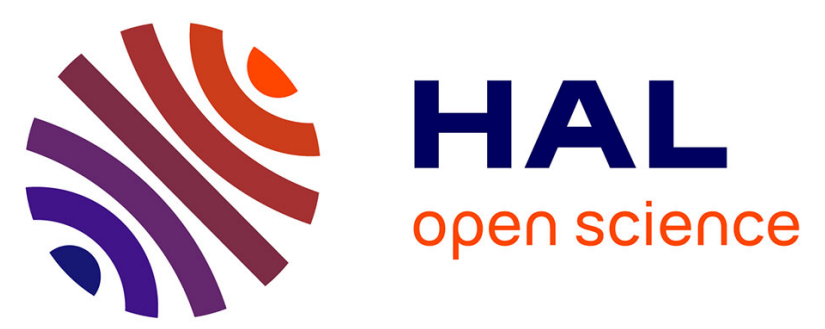

\title{
Venous or Arterial Thromboses after Venoarterial-Extracorporeal Membrane Oxygenation Support: Frequency and Risk Factors
}

Frank Bidar, Aymeric Lancelot, Guillaume Lebreton, Marc Pineton de Chambrun, Matthieu Schmidt, Guillaume Hékimian, Charles Juvin, Nicolas Bréchot, Thibaut Schoell, Pascal Leprince, et al.

\section{To cite this version:}

Frank Bidar, Aymeric Lancelot, Guillaume Lebreton, Marc Pineton de Chambrun, Matthieu Schmidt, et al.. Venous or Arterial Thromboses after Venoarterial-Extracorporeal Membrane Oxygenation Support: Frequency and Risk Factors. The Journal of Heart and Lung Transplantation, 2021, 40 (4), pp.307-315. 10.1016/j.healun.2020.12.007 . hal-03268421

\section{HAL Id: hal-03268421 \\ https: / hal.sorbonne-universite.fr/hal-03268421}

Submitted on 23 Jun 2021

HAL is a multi-disciplinary open access archive for the deposit and dissemination of scientific research documents, whether they are published or not. The documents may come from teaching and research institutions in France or abroad, or from public or private research centers.
L'archive ouverte pluridisciplinaire HAL, est destinée au dépôt et à la diffusion de documents scientifiques de niveau recherche, publiés ou non, émanant des établissements d'enseignement et de recherche français ou étrangers, des laboratoires publics ou privés. 


\section{Venous or Arterial Thromboses after Venoarterial-Extracorporeal}

\section{Membrane Oxygenation Support: Frequency and Risk Factors}

3

4 Frank Bidar, $\mathrm{MD}^{1}$; Aymeric Lancelot, $\mathrm{MD}^{2}$; Guillaume Lebreton, $\mathrm{MD}, \mathrm{PhD}^{3}$; Marc Pineton

5 de Chambrun, $\mathrm{MD}^{1}$; Matthieu Schmidt, MD, $\mathrm{PhD}^{1,4}$; Guillaume Hékimian, $\mathrm{MD}^{1}$; Charles

6 Juvin, $\mathrm{MD}^{3}$; Nicolas Bréchot, $\mathrm{MD} \mathrm{PhD}^{1}$; Thibaut Schoell, $\mathrm{MD}^{3}$; Pascal Leprince, $\mathrm{MD}, \mathrm{PhD}^{3}$;

7 Alain Combes, $\mathrm{MD}, \mathrm{PhD}^{1,4}$; Adrien Bouglé, $\mathrm{MD}, \mathrm{PhD}^{2}$; and Charles-Edouard Luyt, $\mathrm{MD}$,

$8 \mathrm{PhD}^{1,4}$

9

${ }^{1}$ Service de Médecine Intensive Réanimation, Institut de Cardiologie, Assistance PubliqueHôpitaux de Paris (APHP), Sorbonne Université, Hôpital Pitié-Salpêtrière, Paris, France

${ }^{2}$ Département d'Anesthésie-Réanimation, Institut de Cardiologie, APHP, Sorbonne

Université, Hôpital Pitié-Salpêtrière, Paris, France

${ }^{3}$ Service de Chirurgie Cardiaque, Thoracique et Vasculaire, Institut de Cardiologie, APHP, Sorbonne Université, Hôpital Pitié-Salpêtrière, Paris, France.

${ }^{4}$ Sorbonne Université, INSERM, UMRS_1166-ICAN Institute of Cardiometabolism and Nutrition, Paris, France;

\section{Corresponding author}

Charles-Edouard Luyt, MD, PhD, Service de Médecine Intensive Réanimation, Institut de Cardiologie, ICAN, Groupe Hospitalier Pitié-Salpêtrière, 47-83, boulevard de l'Hôpital, 75651 Paris Cedex 13, France. Phone : +33 1421638 24. e-mail: charlesedouard.luyt@aphp.fr

Clinical trial number: Not applicable 
27 Abstract word count: 246 words

28 Total word count: 3154 words

29

30

31 Running title: Vascular complications after VA-ECMO

32

33 Research support: Support was provided solely from institutional sources.

34

35

36 Tweet: Vascular complications - cannula-associated deep vein thrombosis, leg ischemia or

37 delayed arterial stenosis- are frequent after VA-ECMO removal, and should be systematically 38 sought

39 


\section{ABSTRACT}

Background: Although venous thrombosis following venovenous-extracorporeal membrane oxygenation (ECMO) is well described, vascular complications occurring after venoarterialECMO (VA-ECMO) removal have not yet been thoroughly described. Our aim was to evaluate the frequency of vascular (arterial and venous) complications after VA-ECMO removal and try to identify risk factors associated with them.

Methods: Retrospective analysis of data prospectively collected in two ICUs. Consecutive patients successfully weaned-off VA-ECMO during 1 year were screened for cannulaassociated deep-vein thrombosis (CaDVT) or arterial complications (arterial thrombosis/stenosis) using Doppler ultrasonography.

Results: From November 2018 to November 2019, 107 patients (median (IQR) age 54 (4263) years old and median (IQR) days on ECMO support 8 (2-5)) were successfully weanedoff VA-ECMO and included. CaDVT occurred in 44 (41\%) patients and arterial complications in 15 (14\%) (nine acute leg ischemia, one arteriovenous femoral fistula, and five late femoral stenosis). Multivariable analysis retained longer duration of ECMO support (OR, 1.12 per day; 95\% CI, 1.02-1.22), and infection occurring on ECMO (OR, 3.03; 95\% CI, 1.14-8.03) as independent risk factors for CaDVT whereas older age (odds ratio (OR), 0.97 per year; $95 \%$ confidence interval (CI), 0.94-0.99) and prior anticoagulation use (OR 0.21; 95\% CI, 0.06-0.68) were protective factors for CaDVT. No risk factors for arterial complications were identified.

Conclusions: In patients requiring VA-ECMO support, vascular complications occurred frequently after its removal, especially CaDVT. Arterial complications, either early leg ischemia or late arterial stenosis, were observed less often. Strategies aimed at preventing CaDVT after VA-ECMO remain to be determined. 
Venoarterial-extracorporeal membrane oxygenation (VA-ECMO) is used to support patients with heart failure refractory to conventional therapies ${ }^{1}$. The technique exposes the patient's circulating blood to the synthetic surfaces of the circuit that can lead to thrombosis, with subsequent activation of the coagulation cascade, platelets, leukocytes and complement, inducing thrombin generation and hypercoagulability ${ }^{2}$. Moreover, the use of intravascular devices is a known risk factor for developing deep-vein thrombosis (DVT), especially for intensive care unit (ICU) patients ${ }^{3}$. All those changes might contribute to higher thrombosis rates seen in these patients. Whereas the bleeding risks have been widely described ${ }^{4}$, the risk of developing cannula-associated DVT (CaDVT) has only been studied in patients after venovenous (VV)-ECMO, with frequencies ranging from 15 to $80 \%{ }^{5}$. Although some authors found a relationship between CaDVT and the anticoagulation level ${ }^{6}$, the results were not homogeneous across studies ${ }^{7-9}$.

Because patients on VA-ECMO may receive higher anticoagulation levels than those on VV$\mathrm{ECMO}^{10}$, the risk of developing DVT might theoretically be lower but, to date, is unknown. Moreover, the frequency of arterial thrombosis/leg ischemia in VA-ECMO patients after decannulation remains to be determined. Therefore, we designed this study to evaluate the frequencies of venous or arterial thromboses in VA-ECMO patients after decannulation, and to try to identify risk factors associated with those events. 


\section{Patients}

87 All consecutive patients who received VA-ECMO and were successfully weaned-off it in two ICUs between November 2018 and November 2019 were included. Patients who had less than 48 hours of ECMO run, died on-ECMO or those not screened for cannula-related thrombosis were excluded. All the following information was collected prospectively: ICUadmission Simplified Acute Physiology Score (SAPS) II and Sequential Organ-Failure Assessment (SOFA) score; local infectious complications (ie, cannula infection and cannularelated cellulitis) during and after ECMO; ECMO parameters (indication, duration of ECMO support, type of insertion, cannula sizes); anticoagulation parameters (days on heparin, dailyheparin dose, activated partial thromboplastin time (aPTT), anti-Xa activity, fibrinogen, platelets, use of antiplatelet agents); evolution after decannulation (existence of thrombosis, anticoagulation regimen, hemorrhagic or thrombotic complications, thrombosis evolution under treatment), length of ICU stay, hospital mortality.

\section{ECMO Implantation, Anticoagulation and Weaning}

The cannulation technique used was outflow via the femoral vein and inflow via the femoral artery with systematic reperfusion catheter to prevent limb ischemia; when venoarterialvenous-ECMO (VAV-ECMO) was required, another inflow cannula was inserted into the right internal jugular vein. Usual diameter ranges were: 15-19 Fr for the arterial cannula and 21-29 Fr for the venous cannula. ECMO was implanted percutaneously under ultrasound guidance by trained cardiovascular surgeons as first-line choice or surgically, if necessary ${ }^{11}$. 
107 All patients received the same anticoagulation protocol, as previously described ${ }^{4,12}$. After a

108 heparin bolus (5000 IU) at ECMO initiation, all patients were continuously infused with

109 unfractionated heparin (UFH). The heparin dose was adapted, at least once daily, according to

110 the aPTT (expressed as patient-/normal-value ratio, targeting 1.5-2-fold the normal-control

111 value) and clinical tolerance; heparin was stopped when bleeding occurred and restarted once

112 it was controlled. Antithrombin 3 was not routinely measured. The need for heparin

113 discontinuation was defined as any bleeding (at the ECMO implantation site, central or

114 arterial lines, tracheal secretions, ear, nose and throat), with or without hemodynamic impact

115 or hemoglobin decline, judged meaningful by the patient's treating physician. Anticoagulant

116 overdose was defined as an aPTT $>2.5$, corresponding to an absolute value of $\geq 80 \mathrm{~s}$.

117 The membrane oxygenator and its circuitry were checked daily by experienced perfusionists

118 and changed when: fibrin deposition or thrombi had deleterious effects on blood oxygenation;

119 platelet count $(<20$ giga/L) or blood fibrinogen $(<1.5 \mathrm{~g} / \mathrm{L})$ decreased markedly; or

120 intravascular hemolysis (twice-measured free-plasma hemoglobin $>200 \mathrm{mg} / \mathrm{L}$ and no other

121 cause of mechanical hemolysis found). No systematic circuit change was scheduled.

122 According to our local protocol, ECMO was removed after a successful weaning test by a

123 cardiac surgeon ${ }^{13}$. For percutaneous ECMO implantation, the vessels were manually

124 compressed after decannulation during $60 \mathrm{~min}$. In case of persistent bleeding, a surgical

125 correction was performed. When ECMO had been implanted surgically, it was also removed

126 surgically. 
129 The primary objective of the study was to determine the CaDVT frequency after

130 decannulation. Occurrence of arterial complications post-decannulation was also evaluated.

131 CaDVT was routinely assessed by experienced ICU physicians with duplex ultrasonography

132 within the 24 hours following ECMO withdrawal. CaDVT diagnosis was based on vein

133 incompressibility, absence of flow and thrombus presence for peripheral veins (i.e., femoral

134 and jugular), and on thrombus presence in the inferior vena cava ${ }^{14}$. The femoral vein and

135 inferior vena cava were systematically screened for thrombosis in all patients and the jugular

136 vein when needed. When a CaDVT was identified, clinical symptoms and obstruction of the

137 vein (arbitrarily split in 2 categories; obstruction $\leq 50 \%$ of the vessel lumen and obstruction

$138>50 \%$ of the vein lumen) were noted. For inferior vena cava thrombus, thrombus length was

139 noted. Anticoagulation with continuous UFH infusion was started in the ICU for a clinically

140 significant thrombus, as defined by the treating physician, then switched to oral

141 anticoagulation according to physician's choice. Thrombus persistence was verified regularly

142 in the ICU and at the discretion of the medical team caring for the patient. Anticoagulation

143 was stopped when the thrombus was no longer present on duplex ultrasonography. Pulmonary

144 embolism (PE) was diagnosed on computed-tomography (CT) images obtained when

145 clinically suspected but was not routinely ordered.

146 In the case of a clinically suspected complication post-decannulation, arterial thrombotic

147 events were sought and diagnosed with duplex ultrasonography or CT scan. The treatment

148 was chosen in accordance with the surgical team and could include surgical intervention and

149 systemic anticoagulation.

150 All hemorrhagic and arterial or venous thrombotic events, from decannulation until hospital

151 discharge, were recorded for all patients. 


\section{Ethics}

154 In accordance with French law, and as confirmed by the Ethics Committee of the Société de

155 Réanimation de Langue Française (registration number CE SRLF 19-20), informed consent

156 for demographic, physiologic and hospital-outcome data analyses was not obtained because

157 this observational study did not modify existing diagnostic or therapeutic strategies.

158 Nonetheless, patients and/or relatives were informed about the anonymous data collection and

159 told that they could decline inclusion. This database is registered with the Commission

160 Nationale l'Informatique et des Libertés (CNIL, registration no. 1950673).

\section{Statistical Analyses}

163 Results are expressed as median (IQR) or $\mathrm{n}(\%)$. Between-group comparisons were analyzed using Student's $t$-test or the Mann-Whitney $U$-test according to variable's distribution, ie, normal or not for continuous variables. Between-group differences were assessed with chisquare test or Fisher's exact test for nominal variables. A logistic-regression model was used to examine the univariable association of CaDVT and patients' characteristics or ICU events.

168 Thereafter, multivariable logistic-regression model using backward-stepwise variable 169 elimination (with the variable exit threshold set at $P>0.05$ ) tested the factors that were 170 significant in the univariable analyses $(P \leq 0.10)$. Variables included in the model were age

171 (per year increase), prior anticoagulation therapy, days on ECMO support (per day), infection

172 on ECMO support, highest fibrinogen level during ECMO run (per g/L increase),

173 postcardiotomy reason for ECMO and highest platelets level (per Giga/L increase). Between174 variable interactions were sought in the models; variables strongly associated with other(s) 175 were not included in the multivariable model. All reported $P$ values are two-sided and $P<$ 
1760.05 was considered significant. Comparisons were computed using SPSS Version 23 (IBM 177 SPSS, Chicago, IL). 
178

179

180

181

182

183

184

185

186

187

188

189

190

191

192

193

194

195

196

197

198

199

200

\section{RESULTS}

\section{Patient Characteristics}

Between November 2018 and November 2019, 107 patients were successfully weaned-off ECMO and all were included in the study. Their median age was 54 (42-63) years and median time on ECMO support was 8 (2-15) days. The main indications for ECMO were acute on chronic cardiac failure (35.5\%) and postcardiotomy care (31.8\%). VAV-ECMO hook-up was used for five patients. Their baseline characteristics, course on ECMO and outcomes are reported in Table 1.

\section{CaDVT and Arterial Complications}

Among the 107 patients, 44 (41\%) developed CaDVT (Fig. 1). The most frequent CaDVT location was the inferior vena cava (38 patients, including one patient with extension into a subhepatic vein, followed by seven in the femoral vein. Mean \pm SD inferior vena cava thrombus length was $3.4 \pm 1.4 \mathrm{~cm}$, with minimal and maximal size of 1 and $7 \mathrm{~cm}$, respectively. Seven patients had a cannula in the right internal jugular vein, five because of VAV-ECMO lines and two because of a return cannula in the pulmonary artery (venoarterialpulmonary-ECMO) for right ventricular support after left ventricular assist-deviceimplantation. Among them, three were diagnosed with jugular vein CaDVT. Multiple thromboses were found in four of the 44 (9\%): two patients had inferior vena cava and femoral vein CaDVTs, one had inferior vena cava and jugular vein CaDVTs and one had bilateral femoral vein thromboses, for a total of 48 CaDVTs, among which 19 (40\%) were large, defined as $>50 \%$ lumen obstruction. All inferior vena cava and jugular vein thromboses were asymptomatic, whereas $43 \%$ of patients with femoral vein CaDVTs had unilateral swelling. 
201

202

203

204

205

206

207

208

209

210

211

212

213

214

215

216

217

218

219

220

221

222

223

Arterial complications were diagnosed in $15(14 \%)$ of the 107 patients. Ten patients had early symptoms: seven had acute leg ischemia treated with thrombectomy, two experienced femoral or iliac dissection and one developed a femoral arteriovenous fistula. Five patients had late symptoms (that appeared 4-30 days after ECMO removal), all five had CT-scan-diagnosed femoral or iliac artery stenosis.

Patients' outcomes are reported in Table 1. Among the patients with CaDVTs, 37 were treated with anticoagulation therapy, 27 had favorable outcomes with duplex ultrasonography showing thrombus disappearance, three died shortly after ECMO withdrawal and seven were lost to follow-up. Anticoagulation was administered for 7 to $>60$ days. Two CaDVT-group patients were diagnosed with PE after ECMO decannulation: one had distal PE and favorable outcome after anticoagulation therapy, the other had proximal PE and died in-ICU of septic and hemorrhagic shock. The hemorrhagic complication and in-hospital-mortality rates were the same for patients with CaDVT or without.

\section{CaDVT Risk Factors}

CaDVT-associated factors are reported in Tables 1 and 2. CaDVT-group patients were younger and less frequently received pre-ECMO anticoagulant therapy, whereas severity scores at admission and ECMO start, and history of malignancy or thromboembolic disease were similar for the two groups. Time on ECMO was significantly longer for patients who developed CaDVT. Hemostasis parameters were similar for patients with CaDVT or without, except for highest fibrinogen level during the ECMO run that was higher in patients with CaDVT than those without. The median aPTT ratio and median percentage of days with aPTT in the therapeutic zone (ie, 1.5-2-fold the normal-control value), the total UFH dose received, 
224 days on UFH or the median platelet count did not differ between groups. Patients who

225 developed CaDVT after ECMO removal more frequently had an infection during the ECMO

226 run than those without CaDVT, whereas the infection rate before ECMO implantation and

227 after ECMO removal did not differ between patients with CaDVT or without. The cannula-

228 related-infection rate was doubled for patients with CaDVT than those without $(P=0.06)$.

229 Multivariable analysis retained ECMO runtime and concurrent infection as independent risk

230 factors significantly associated with CaDVT, whereas older age and prior anticoagulant use

231 were protective risk factors (Table 3).

232

233 Risk Factors for Arterial Complications

234 Clinical and laboratory parameters as a function of arterial complications or not are given in

235 Tables 4 and 5; none was associated with having an arterial complication in our population. 


\section{DISCUSSION}

239 The results of this study showed that arterial thrombosis and CaDVT were frequent in VA-

240 ECMO-treated patients, with the latter occurring in $41 \%$ of patients and being more frequent

241 than the former. Also, several risk factors for developing CaDVT in this population were

242 identified, namely: infection on ECMO support, longer duration of ECMO support, while

243 older age and anticoagulant therapy prior to ECMO support were protective factors. To the

244 best of our knowledge, vascular complications in adult patients after weaning-off VA-ECMO

245 have not been examined previously; all earlier studies included only patients given VV-

246 ECMO support and focused on DVT $^{7}$. Our $41 \%$ CaDVT rate for VA-ECMO is in agreement

247 with VV-ECMO DVT rates for those series, which ranged from $18 \%$ to $80 \%$.

249 Pathogenesis and risk factors for CaDVT

250 The exact pathogenesis of venous thrombosis in ECMO patients is not fully understood: the 251 origin of thrombus is probably the cannula itself, a thrombogenic surface that may activate 252 coagulation cascade. Venous stasis due to reduction in venous diameter may also play a role.

253 We were able to identify, in our study, specific risk factors for CaDVT. First, we found that 254 infection on ECMO was a major risk factor for CaDVT. Infection induces inflammatory 255 processes that might have enhanced thrombogenic activity in these patients and local 256 (cannula-related) infection might have played a role by locally increasing thrombogenicity ${ }^{15}$. 257 Infection has not previously been specifically described as a risk factor for CaDVT; one study 258 reported a higher CaDVT rate when bacterial pneumonia-related acute respiratory distress 259 syndrome was the indication for ECMO, as compared to other situations requiring ECMO; ; 260 but other nosocomial infections have not been investigated ${ }^{9}$. 
261 Second, and as found by others ${ }^{6}$, ECMO duration was longer for the CaDVT group. That

262 finding might be explained by a longer cannulation time being associated with a higher risk of 263 stasis and, thus, thrombosis formation.

264 We also found that prior anticoagulation therapy had a protective effect against CaDVT. In 265 addition to ECMO, some patients had another indication for anticoagulation, mostly atrial 266 fibrillation or mechanical valve prosthesis, conditions that could have influenced 267 anticoagulation level and therefore CaDVT occurrence ${ }^{16}$. Although we were unable to 268 establish any direct relationship between coagulation parameters during ECMO course and 269 the risk of developing CaDVT, two studies reported a protective effect of anticoagulation ${ }^{6,8,9}$.

270 These differences might be partly explained by the difficult evaluation of anticoagulation

271 level in ECMO patients, since these latter experienced potentially multiple hemostasis

272 disorders (induced by the ECMO itself and/or by associated-organ failures, antiplatelet agent 273 use...) ${ }^{17}$.

274 Interestingly, developing a CaDVT did not impact mortality. The ICU length of stay was 275 longer for CaDVT patients but that excess is probably explained by their longer ECMO 276 durations.

\section{Arterial complications after ECMO removal}

279 Another study originality was examining arterial complications following VA-ECMO, 280 although small number of events in our study precluded identification of any risk factors 281 associated with arterial complications. We found that the arterial complication rate was lower than that of CaDVT, however, because most events were clinically apparent, we could have missed some clinically less obvious episodes. Pertinently, some of those events could happen

284 immediately after ECMO removal (leading to leg ischemia), but also later, with arterial 
285

stenosis. It is important that intensivists be aware of the potential latency of this rare complication, to follow their patients after decannulation and actively look for it, in particular in patients who might need repeated vascular procedures such as chronic heart failure or heart transplant patients. Regardless of the type of arterial complication, they often required more aggressive treatment than CaDVT, involving interventional radiologists and/or surgeons.

\section{Potential implications of our results}

Several implications of our results that could help clinicians taking care of those patients should be discussed. Firstly, physicians should monitor venous thrombosis during ECMO course and immediately after ECMO removal. Indeed, although our data don't allow knowing whether or not monitoring venous thrombosis before ECMO removal should be interesting, it seems logical to do so: if there is venous thrombosis around cannula before ECMO removal, the likelihood of having venous thrombosis after ECMO removal is very high. Moreover, due to the high rate of CaDVT, systematic screening for CaDVT after ECMO removal should be recommended.

The second implication refers to treatment of CaDVT, although this latter is not standardized. Venous thrombectomy during decannulation should be avoided, since this procedure may injured endothelium and increase the risk of venous thrombus formation. According to guidelines ${ }^{18}$, a 3-month anticoagulation regimen is recommended for catheter-related DVT.

Our practice and recommendation is to start anticoagulation in the ICU, when the thrombosis is considered clinically significant and the bleeding risk is acceptable, taking into account that VA-ECMO patients have a higher risk of bleeding at the decannulation site than those on VVECMO. We then regularly monitor the thrombus with ultrasounds and stop anticoagulation 
308 when is disappears. This approach seemed to be safe, since the hemorrhagic complication rate 309 after ECMO decannulation was the same for no-CaDVT and CaDVT groups.

310 The last implication refers to arterial complications following ECMO removal. Indeed, 311 arterial complications occurring during or early after ECMO removal is usually obvious and 312 easy to diagnose since physicians are aware of potential acute leg ischemia; whereas 313 complication occurring late after ECMO removal may be less obvious for clinicians. They 314 should be aware that arterial stenosis may occur late after ECMO removal and systematically 315 screen their patient to look for it.

\section{Study limitations}

318 Our study has several limitations that should be addressed. Firstly, we include patients after

319 ECMO removal and focused our study on vascular complications after ECMO removal.

320 Therefore, we didn’t retrieve vascular complications occurring during ECMO support.

321 Secondly, the retrospective design of our study exposes to inherent bias of such studies.

322 However, all data were collected prospectively, so few data are missing. Moreover, all 323 consecutive patients were included. Third, the use of ultrasound to diagnose venous 324 thrombosis-and in particular inferior vena cava thrombosis- may be disputable. Fourth, no 325 pre-ECMO evaluations were available for our patients; therefore, we cannot exclude that 326 some patients might have had preexisting vascular lesions, especially femoral artery stenosis.

327 However, we think that is unlikely, because these lesions were not present shortly after 328 decannulation and only appeared on follow-up images. Moreover, it is highly unlikely that 329 some patients with preexisting femoral stenosis could have undergone VA-ECMO with a 330 femoral cannula without any clinical manifestation. Fifth, the thrombosis rate might have 331 been underestimated because CaDVT was diagnosed ultrasonographically; in particular 
332 extension of femoral thrombosis to iliac veins, which are difficult to evaluate in the ICU

333 setting. Similarly, some patients with asymptomatic arterial complications may have been

334 missed. Sixth, follow-up was not standardized and thrombosis persistence was evaluated at 335 different times for each patient depending on the patient's therapeutic pathway. Seventh, we 336 didn't perform specific coagulation test, and didn't monitor antithrombin 3 levels during 337 ECMO course, whereas coagulation factors levels may be altered during ECMO and may

338 have play a role in venous thrombosis by inducing prothrombotic state ${ }^{19}$. However, a recent 339 small randomized controlled trial failed to demonstrate any beneficial effect of antithrombin 340 supplementation during ECMO run ${ }^{20}$. Finally, PE might have also been underdiagnosed 341 because CT scans were only ordered when clinical signs were present ${ }^{21}$.

\section{Conclusion}

344 In conclusion, vascular complications after VA-ECMO removal are frequent. CaDVT was the 345 most frequent and should be actively sought in every patient after VA-ECMO explantation, 346 especially patients with prolonged ECMO runs, or when an on-ECMO infection occurred.

347 Arterial complications were less frequent, could occur early after ECMO withdrawal (acute 348 ischemia) or later (arterial stenosis). Further studies are needed to evaluate the precise 349 duration of anticoagulation in patients with CaDVT. 
352 Conflicts of interest: C.-E.L. reports personal fees from Merck Sharp and Dohme, Thermo 353 Fischer Brahms, Biomérieux, Carmat, Bayer Healthcare, Aerogen and grants from Bayer 354 Healthcare, outside the scope of the submitted work. M.S. reports lecture fees from Maquet, 355 Getinge and Fresenius, outside the scope of the submitted work. Other authors declare that 356 they have no conflicts of interest.

358 Author contribution: FB and CEL drafted the study design, analyzed the results and drafted 359 the manuscript. All authors participated in the data collection, final manuscript preparation 360 and agreed with the latest manuscript.

362 Funding source: None

364 Acknowledgments: The authors thank Janet Jacobson for her help during the preparation of 365 the manuscript. 
367 TABLE 1 Characteristics of the Study Population According to CaDVT Status after VA-

368 ECMO Removal

\begin{tabular}{lcccr}
\hline & All & \multicolumn{2}{c}{ CaDVT } & \\
\cline { 3 - 4 } Characteristic & $(\mathrm{n}=107)$ & No $(\mathrm{n}=63)$ & Yes $(\mathrm{n}=44)$ & $P$ \\
& & & & \\
& & & & \\
& & & & \\
& $54(42-63)$ & $58(45-67)$ & $38-60)$ & 0.02 \\
Age, year & $72(67.3)$ & $39(61.9)$ & $33(75)$ & 0.16 \\
Male sex & $25.3(22-28)$ & $25.7(22.6-29.4)$ & $24.2(21-27.1)$ & 0.26 \\
Body mass index, $\mathrm{kg} / \mathrm{m}^{2}$ & & & & \\
Comorbidities & $10(9.3)$ & $8(12.7)$ & $2(1.9)$ & 0.15 \\
Cancer & $2(1.9)$ & 0 & $2(4.5)$ & 0.17 \\
Hemopathy & $4(3.7)$ & $3(4.8)$ & $1(2.3)$ & 0.64 \\
Venous thromboembolic disease & $49(45.8)$ & $31(49.2)$ & $18(40.9)$ & 0.39 \\
Heart failure & $2(1.9)$ & $2(3.2)$ & 0 & 0.51 \\
Chronic inflammatory disease & $3(2.8)$ & $3(4.8)$ & 0 & 0.27 \\
Venous insufficiency & $29(27.1)$ & $22(34.9)$ & $7(15.9)$ & 0.03 \\
Anticoagulation therapy & &
\end{tabular}

Severity scores

SAPS II at admission

$\begin{array}{cccc}49(37-71) & 49(37-73) & 52.5(36.5-70.7) & 0.95 \\ 10(7-13) & 10(7-13) & 12(8-15) & 0.28 \\ 12(9-14) & 11(10-13) & 12(8-15) & 0.44\end{array}$

SOFA at ECMO start

Reason for ECMO

Acute coronary syndrome

$22(20.6) \quad 12(19.0)$

$10(22.7) \quad 0.64$

Acute on chronic heart failure

38 (35.5)

$20(31.7)$

$18(40.9) \quad 0.33$

Myocarditis

$7(6.5)$

$3(4.8)$

$4(9.1)$

0.44

Septic shock

Pulmonary embolism

$3(2.8)$

1 (1.6)

$1(0.9)$

1 (1.6)

$2(4.5)$

0.57

Cardiac arrest

$24(22.4)$

$14(22.2)$

0

1

Postcardiotomy

34 (31.8)

$26(41.3)$

$10(22.7)$

0.95

Percutaneous cannulation

90/105 (85.7)

$54 / 63(85.7)$

$8(18.2)$

0.01

Venous cannula diameter, n/n (\%)

0.96 
$<25 \mathrm{Fr}$

$25 \mathrm{Fr}$

$>25 \mathrm{Fr}$

Days of ECMO support

Events during ICU stay

Use of aspirin

Use of $\geq 2$ antiplatelet agents

Infection before ECMO start ${ }^{\mathrm{a}}$

Pulmonary

Other

Infection on $\mathrm{ECMO}^{\mathrm{a}}$

Pulmonary

Cannula-related

Other

Infection after ECMO removal $^{\mathrm{a}}$

Pulmonary

Cannula-related

Other

Heart transplant

Heparin-induced

thrombocytopenia

Oxygenator change

$\begin{array}{ccc}9 / 100(9) & 5 / 60(8.3) & 4 / 40(10) \\ 81 / 100(81) & 49 / 60(81.7) & 32 / 40(80) \\ 10 / 100(10) & 6 / 60(10) & 4 / 40(10)\end{array}$

$8(2-15)$

7 (4-10)

$10(7-16)$

0.001

$\begin{array}{cccc}34(31.8) & 23(36.5) & 11(25) & 0.21 \\ 23(21.5) & 14(22.2) & 9(20.5) & 0.83 \\ 31 / 106(29.2) & 16 / 63(25.4) & 15 / 43(34.9) & 0.29 \\ 30 / 106(28.6) & 5 / 63(7.9) & 11 / 43(25) & 0.02 \\ 15 / 106(14.1) & 5 / 63(17.5) & 4 / 43(9.3) & 0.27\end{array}$

$47(43.9) \quad 20(31.7)$

27 (61.4) $\quad 0.002$

30 (28.6)

12 (19)

18 (40.9)

0.017

22 (20.6)

9 (14.3)

13 (29.5)

0.06

$9(8.4)$

$4(6.3)$

42/102 (41.2)

25/61 (41)

5 (11.4)

0.48

22/102 (21.6) 13/61(21)

$17 / 41(41.5)$

0.96

16/102 (15.6) 9/61 (14.8)

9/41 (21.9)

1

14/102 (13.7)

10/61 (16.3)

$7 / 41(15.9)$

$4 / 41(9.7)$

0.39

34 (31.8)

$20(31.7)$

14 (31.8)

0.97

$\begin{array}{cc}1 / 106(2.3) & 0 / 62 \\ 17 / 106(16.3) & 8 / 62(12.9)\end{array}$

$1 / 44(2.3)$

0.42

9/42 (21.4)

0.25

Outcomes

Hemorrhagic complications

$\begin{array}{cccc}30 / 104(28.8) & 12 / 61(27.9) & 18 / 43(29.5) & 0.86 \\ 20(12-28) & 20(10-24) & 24(13-35) & 0.047 \\ 17(15.9) & 7(11.1) & 10(22.7) & 0.11\end{array}$

ICU length of stay, days

Hospital mortality

$17(15.9)$

$10(22.7)$

0.11

369 Results are expressed as median (IQR) or $\mathrm{n}(\%)$. CaVDT $=$ cannula-associated deep-vein

370 thrombosis; VA-ECMO = venoarterial-extracorporeal membrane oxygenation; SAPS =

371 Simplified Acute Physiology Score; SOFA = Sequential Organ-Failure Assessment; ICU =

372 intensive care unit.

$373{ }^{a}$ Whatever the site of infection 
TABLE 2 Blood-Coagulation Parameters on VA-ECMO Support According to CaDVT Status after Its Removal

\begin{tabular}{|c|c|c|c|c|}
\hline \multirow[b]{2}{*}{ Characteristic } & \multirow{2}{*}{$\begin{array}{c}\text { All } \\
(\mathrm{n}=107)\end{array}$} & \multicolumn{2}{|c|}{ CaDVT } & \multirow[b]{2}{*}{$P$ Value } \\
\hline & & No $(n=63)$ & Yes $(n=44)$ & \\
\hline Daily UFH dose, IU & $8004(4614-13429)$ & $\begin{array}{c}7695(3087- \\
13663)\end{array}$ & $\begin{array}{c}8301(5403- \\
12810)\end{array}$ & 0.75 \\
\hline Days on UFH therapy, $\%^{a}$ & $90.6(66.6-100)$ & $88.8(66.6-100)$ & $100(66.6-100)$ & 0.45 \\
\hline aPTT ratio & $1.49(1.32-1.72)$ & $1.48(1.34-1.71)$ & $1.50(1.25-1.72)$ & 0.81 \\
\hline Days with aPTT ratio $<1.2, \%^{a}$ & $20(0-40)$ & $20(0-43)$ & $21.5(8-40)$ & 0.57 \\
\hline Days with aPTT ratio $\geq 1.2$ and $<1.5, \%^{a}$ & $30.7(20-50)$ & $33.3(22-50)$ & $27.5(17-59)$ & 0.59 \\
\hline Days with aPTT ratio $\geq 1.5$ and $<2, \%^{a}$ & $23(0-33)$ & $25(0-38)$ & $18(0-32)$ & 0.25 \\
\hline Days with aPTT ratio $\geq 2, \%^{a}$ & $0(0-22)$ & $0(0-20)$ & $2(0-23)$ & 0.18 \\
\hline Days with anti-Xa activity $<0.2 \mathrm{IU} / \mathrm{mL}, \%^{a}$ & $50(25-75)$ & $50(25-67)$ & $53.9(34-80)$ & 0.21 \\
\hline Days with anti-Xa activity $\geq 0.2$ and $<0.5$ & $0(0-16,7)$ & $0(0-23)$ & $0(0-15.9)$ & 0.78 \\
\hline \multicolumn{5}{|l|}{$\mathrm{IU} / \mathrm{mL}, \%^{\mathrm{a}}$} \\
\hline Days with anti-Xa activity $\geq 0.5 \mathrm{IU} / \mathrm{mL}, \%^{\mathrm{a}}$ & $0(0-0)$ & $0(0-0)$ & $0(0-0)$ & 0.32 \\
\hline Days with unknown anti-Xa activity, $\%^{a}$ & $25(0-50)$ & $25(0-50)$ & $25(3-43)$ & 0.69 \\
\hline Fibrinogen, $\mathrm{g} / \mathrm{L}$ & $3.82(3.08-5.07)$ & $3.58(3-5)$ & $4.2(3.4-5.3)$ & 0.07 \\
\hline Lowest fibrinogen level & $2.2(1.7-3.3)$ & $2.2(1.67-2.87)$ & $2.35(1.77-3.42)$ & 0.34 \\
\hline Highest fibrinogen level & $5.5(4.5-7)$ & $5.15(4.37-6.6)$ & $6.55(4.5-7.5)$ & 0.034 \\
\hline Days with fibrinogen $<2 \mathrm{~g} / \mathrm{L}, \%^{\mathrm{a}}$ & $0(0-11.1)$ & $0(0-16.7)$ & $0(0-7.3)$ & 0.18 \\
\hline Days with fibrinogen $2 \geq$ and $<4 \mathrm{~g} / \mathrm{L}, \%^{\mathrm{a}}$ & $47.4(0.14-0.66)$ & $50(14.3-66.7)$ & $40(14.5-67.6)$ & 0.43 \\
\hline
\end{tabular}


Days with fibrinogen $\geq 4 \mathrm{~g} / \mathrm{L}, \%^{a}$

Platelets, Giga/L

Lowest platelet count,

Highest platelet count,

Days with platelets $<150, \%^{\text {a }}$

Days with platelets $\geq 150$ and $<400, \%^{a}$

Days with platelets $\geq 400, \%$ a

$\begin{array}{cccc}44.4(0.1-0.75) & 33.3(8.3-75) & 51.3(12.5-75) & 0.27 \\ 110(82-142) & 113(85.8-140) & 100(79.2-152) & 0.72 \\ 62(43-95) & 70.5(46-96) & 55(41-92) & 0.22 \\ 188(142-235) & 182(142-217) & 207(140-250) & 0.17 \\ 85.7(0.6-1) & 87.5(66.7-100) & 82.6(50-100) & 0.63 \\ 12.5(0-37.5) & 12.5(0-31) & 13.4(0-40) & 0.95 \\ 0(0-0) & 0(0-0) & 0(0-0) & 0.09\end{array}$

Results are expressed as median (IQR). VA-ECMO = venoarterial-extracorporeal membrane oxygenation; CaVDT = cannula-associated deepvein thrombosis; $\mathrm{UFH}=$ unfractionated heparin; IU = international unit; aPTT = activated partial thrombin time.

${ }^{a}$ Expressed as the ratio of the percentage of days/the total number of days on ECMO. 
TABLE 3 Multivariable Analysis of Factors Associated with CaDVT after VA-ECMO

\begin{tabular}{lcc}
\hline Parameter & $\begin{array}{c}\text { Odds Ratio } \\
(95 \% \mathrm{CI})\end{array}$ & $P$ Value \\
\hline Age, per year & $0.97(0.94-0.99)$ & 0.02 \\
Prior anticoagulation therapy & $0.21(0.06-0.68)$ & 0.009 \\
Days on ECMO support, per day & $1.12(1.02-1.22)$ & 0.02 \\
Infection on ECMO support & $3.03(1.14-8.03)$ & 0.02
\end{tabular}

CaDVT $=$ cannula-associated deep-vein thrombosis; $\mathrm{C}=$ confidence interval; VA-ECMO $=$ venoarterial-extracorporeal membrane oxygenation.

Variables entered into the model were age (per year increase), prior anticoagulation therapy, days on ECMO support (per day), infection on ECMO support, highest fibrinogen level during ECMO run (per g/L increase), postcardiotomy reason for ECMO and highest platelets level (per Giga/L increase). 
TABLE 4 Characteristics of the Study Population According to Arterial Complication Status after VA-ECMO Removal

Arterial Complication

$\begin{array}{llll}\text { Characteristic } & \text { All }(\mathrm{n}=107) & \text { No }(\mathrm{n}=92) & \text { Yes }(\mathrm{n}=15)\end{array} \quad P$ Value

\begin{tabular}{|c|c|c|c|c|}
\hline Age, year & $54(42-63)$ & $56.5(44-62)$ & $50(20-67)$ & 0.27 \\
\hline Male sex & $72(67.3)$ & $64(69.6)$ & $8(53.3)$ & 0.21 \\
\hline Body mass index, $\mathrm{kg} / \mathrm{m}^{2}$ & $25.3(22-28)$ & $25.3(22-28.7)$ & $25.1(22-27.1)$ & 0.92 \\
\hline \multicolumn{5}{|l|}{ Comorbidities } \\
\hline Cancer & $10(9.3)$ & $9(9.8)$ & $1(6.7)$ & 1 \\
\hline Hemopathy & $2(1.9)$ & $1(1.1)$ & $1(6.7)$ & 0.26 \\
\hline Venous thromboembolic disease & $4(3.7)$ & $4(4.3)$ & 0 & 1 \\
\hline Heart failure & $49(45.8)$ & $45(48.9)$ & $4(26.7)$ & 0.16 \\
\hline Chronic inflammatory disease & $2(1.9)$ & $2(2.2)$ & 0 & 1 \\
\hline Venous insufficiency & $3(2.8)$ & $3(3.3)$ & 0 & 1 \\
\hline Anticoagulation therapy & $29(27.1)$ & $27(29.3)$ & $2(13.3)$ & 0.35 \\
\hline \multicolumn{5}{|l|}{ Severity scores } \\
\hline SAPS II at admission & $49(37-71)$ & $48(36-70)$ & $63(47-74)$ & 0.14 \\
\hline SOFA at admission & $10(7.25-13)$ & $10(7-13)$ & $12(8-14)$ & 0.53 \\
\hline SOFA at ECMO start & $12(9-14)$ & $11(9-14)$ & $12(10-15)$ & 0.45 \\
\hline \multicolumn{5}{|l|}{ Reason for ECMO } \\
\hline Acute coronary syndrome & $22(20.6)$ & $19(20.7)$ & $3(20)$ & 1 \\
\hline Acute on chronic heart failure & $38(35.5)$ & $36(39.1)$ & $2(13.3)$ & 0.08 \\
\hline Myocarditis & $7(6.5)$ & $5(5.4)$ & $2(13.3)$ & 0.25 \\
\hline Septic shock & $3(2.8)$ & $3(3.3)$ & 0 & 1 \\
\hline Pulmonary embolism & $1(0.9)$ & $1(1.1)$ & 0 & 1 \\
\hline Cardiac arrest & $24(22.4)$ & $20(21.7)$ & $4(26.7)$ & 0.74 \\
\hline Postcardiotomy & $34(31.8)$ & $29(31.5)$ & $5(33.3)$ & 1 \\
\hline Percutaneous cannulation & $90 / 105(85.7)$ & $78 / 90(86.7)$ & $12 / 15(80)$ & 0.49 \\
\hline Arterial cannula diameter, n/n (\%) & & & & 0.65 \\
\hline$<17 \mathrm{Fr}$ & $10 / 101(9.9)$ & 8/89 (9) & $2 / 12(16.7)$ & \\
\hline $17 \mathrm{Fr}$ & $77 / 101(76.2)$ & $69 / 89(77.5)$ & $8 / 12(66.7)$ & \\
\hline
\end{tabular}


$>17 \mathrm{Fr}$

Days of ECMO support

Events during ICU stay

Use of aspirin

Use of $\geq 2$ antiplatelet agents

Infection before ECMO start

Pulmonary

Other

Infection on ECMO

Pulmonary

Cannula-related

Other

Infection after ECMO removal

Pulmonary

Cannula-related

Other

Heart transplant

Heparin-induced

thrombocytopenia

Oxygenator change

Outcomes

Hemorrhagic complications

ICU length of stay, days

Hospital mortality

$$
14 / 101(13.9) \quad 12 / 89(13.5) \quad 2 / 12(16.7)
$$

$$
8(2-15) \quad 8(5-13) \quad 8(4-11) \quad 0.49
$$

$34(31.8) \quad 29(31.5) \quad 5(33.3)$

$23(21.5) \quad 20(21.7) \quad 3(20) \quad 1$

$31 / 106(29.2) \quad 24 / 91(26.4) \quad 7 / 15(46.7) \quad 0.13$

$16 / 106(15) \quad 13 / 91(14.3) \quad 3 / 15(20) \quad 0.7$

$15 / 106(14) \quad 11 / 91(12) \quad 4 / 15(26.7) \quad 0.22$

$\begin{array}{llll}47(43.9) & 41(44.6) & 6(40) & 0.79\end{array}$

$30(28) \quad 26(28.3) \quad 4(26.7) \quad 1$

$\begin{array}{llll}22(20.6) & 21(22.8) & 1(6.7) & 0.15\end{array}$

$9(8.4) \quad 7(7.6) \quad 2(13.3) \quad 0.61$

42/102(41.2) 33/88(37.5) $\quad 9 / 14(64.3) \quad 0.06$

$22 / 102(21.6) \quad 18 / 88(20.5) \quad 4 / 14(28.5) \quad 0.5$

$16 / 102(15.6) \quad 9 / 88(10.2) \quad 7 / 14(50) \quad 0.001$

$14 / 102(13.7) \quad 13 / 88(14.8) \quad 1 / 14(7.1) \quad 0.69$

$\begin{array}{rccc}34(31.8) & 31(33.7) & 3(20) & 0.38 \\ 1 / 106(2.3) & 0 / 91 & 1 / 15(6.7) & 0.14 \\ 17 / 104(16.3) & 17 / 89(19.1) & 0 / 15 & 0.12\end{array}$

$\begin{array}{cccc}30 / 104(28.8) & 25 / 89(28) & 5 / 15(33.3) & 0.62 \\ 20(12-28) & 20(12-28) & 21(17-50) & 0.16 \\ 17(15.9) & 16(17.4) & 1(6.7) & 0.32\end{array}$

Results are expressed as median (IQR) or $\mathrm{n}(\%)$. VA-ECMO = venoarterial-extracorporeal membrane oxygenation; SAPS = Simplified Acute Physiology Score; SOFA = Sequential Organ-Failure Assessment; ICU = intensive care unit. 
TABLE 5 Hemostasis Parameters on VA-ECMO Support According to Arterial Complication Status after Its Removal

\begin{tabular}{|c|c|c|c|c|}
\hline \multirow[b]{2}{*}{ Parameter } & \multirow[b]{2}{*}{ All $(\mathrm{n}=107)$} & \multicolumn{2}{|c|}{ Arterial Complication } & \multirow[b]{2}{*}{$P$ Value } \\
\hline & & No $(\mathrm{n}=92)$ & Yes $(n=15)$ & \\
\hline Daily UFH dose, IU & 8004 (4614-13429) & $8231(4620-13330)$ & $\begin{array}{c}7613(3105- \\
16942)\end{array}$ & 0.93 \\
\hline Days on UFH therapy, $\%^{a}$ & $90.6(66.6-100)$ & $100(66.6-100)$ & $77(50-100)$ & 0.16 \\
\hline aPTT ratio & $1.49(1.32-1.72)$ & $1.49(1.33-1.72)$ & $1.47(1.25-1.73)$ & 0.16 \\
\hline Days with aPTT ratio $<1.2, \%^{\mathrm{a}}$ & $20(0-40)$ & $20(0-40)$ & $12.5(0-44)$ & 0.55 \\
\hline Days with aPTT ratio $\geq 1.2$ and $<1.5, \%^{\text {a }}$ & $30.7(20-50)$ & $29(19-50)$ & $41(25-60)$ & 0.36 \\
\hline Days with aPTT ratio $\geq 1.5$ and $<2, \%^{\text {a }}$ & $23(0-33)$ & $23(0-33)$ & $25(0-42)$ & 0.92 \\
\hline Days with aPTT ratio $\geq 2, \%^{a}$ & $0(0-22)$ & $0(0-21.7)$ & $0(0-28.6)$ & 0.70 \\
\hline Days with anti-Xa activity $<0.2 \mathrm{IU} / \mathrm{mL}, \%^{\mathrm{a}}$ & $50(25-75)$ & $50(25-78)$ & $36.3(25-50)$ & 0.15 \\
\hline $\begin{array}{l}\text { Days with anti-Xa activity } \geq 0.2 \text { and }<0.5 \\
\mathrm{IU} / \mathrm{mL}, \%^{\text {a }}\end{array}$ & $0(0-16,7)$ & $0(0-16.5)$ & $0(0-28.6)$ & 0.55 \\
\hline Days with anti-Xa activity $\geq 0.5 \mathrm{IU} / \mathrm{mL}, \%^{\mathrm{a}}$ & $0(0-0)$ & $0(0-0)$ & $0(0-14.3)$ & 0.19 \\
\hline Days with unknown anti-Xa activity, $\%^{a}$ & $25(0-50)$ & $25(0-50)$ & $25(0-60)$ & 0.75 \\
\hline Fibrinogen, $\mathrm{g} / \mathrm{L}$ & $3.82(3.08-5.07)$ & $3.8(3-5.14)$ & $4.15(3.15-4.47)$ & 0.92 \\
\hline Lowest fibrinogen level, & $2.2(1.7-3.3)$ & $2.2(1.7-3.3)$ & $2.5(1.6-3.5)$ & 0.73 \\
\hline Highest fibrinogen level, & $5.5(4.5-7)$ & $5.4(4.45-7)$ & $6(4.9-7)$ & 0.81 \\
\hline Days with fibrinogen $<2, \%^{a}$ & $0(0-11)$ & $0(0-11)$ & $0(0-9)$ & 0.30 \\
\hline
\end{tabular}


Days with fibrinogen $\geq 2$ and $<4, \%^{a}$

$\begin{array}{cccc}47.4(0.14-0.66) & 46(15-66) & 54(8-81) & 0.46 \\ 44.4(0.1-0.75) & 42(10-75) & 45(9-85) & 0.89 \\ 110(82-142) & 106(81-141) & 118(89-165) & 0.26 \\ 62(43-95) & 61(42-91) & 81(52-109) & 0.08 \\ 188(142-235) & 188(140-233) & 187(145-262) & 0.91 \\ 85.7(0.6-1) & 83(60-100) & 87.5(67-100) & 0.51 \\ 12.5(0-37.5) & 12.5(0-37.5) & 12.5(0-33) & 0.70 \\ 0(0-0) & 0 & 0 & \end{array}$

Days with fibrinogen $\geq 4, \%$ a

Platelets, Giga/L

Lowest platelet count

Highest platelet count

Days with platelets $<150, \%^{a}$

$0(0-0)$

0

$$
\begin{aligned}
& .46 \\
& 0.89 \\
& .26
\end{aligned}
$$

Days with platelets $\geq 150$ and $<400, \%^{a}$

Days with platelets $\geq 400, \%$ a

Results are expressed as median (IQR). VA-ECMO = venoarterial-extracorporeal membrane oxygenation; CaVDT = cannula-associated deep vein thrombosis; $\mathrm{UFH}=$ unfractionated heparin; IU = international unit; aPTT = activated partial thrombin time.

${ }^{a}$ Expressed as the ratio of the percentage of days/the total number of days on ECMO. 
Figure 1 - Study flow chart. VA-ECMO = venoarterial extracorporeal membrane oxygenation; DVT = deep-vein thrombosis; CaDVT = cannula-associated DVT; IVC = inferior vena cava; $\mathrm{FV}=$ femoral vein; JV = jugular vein.

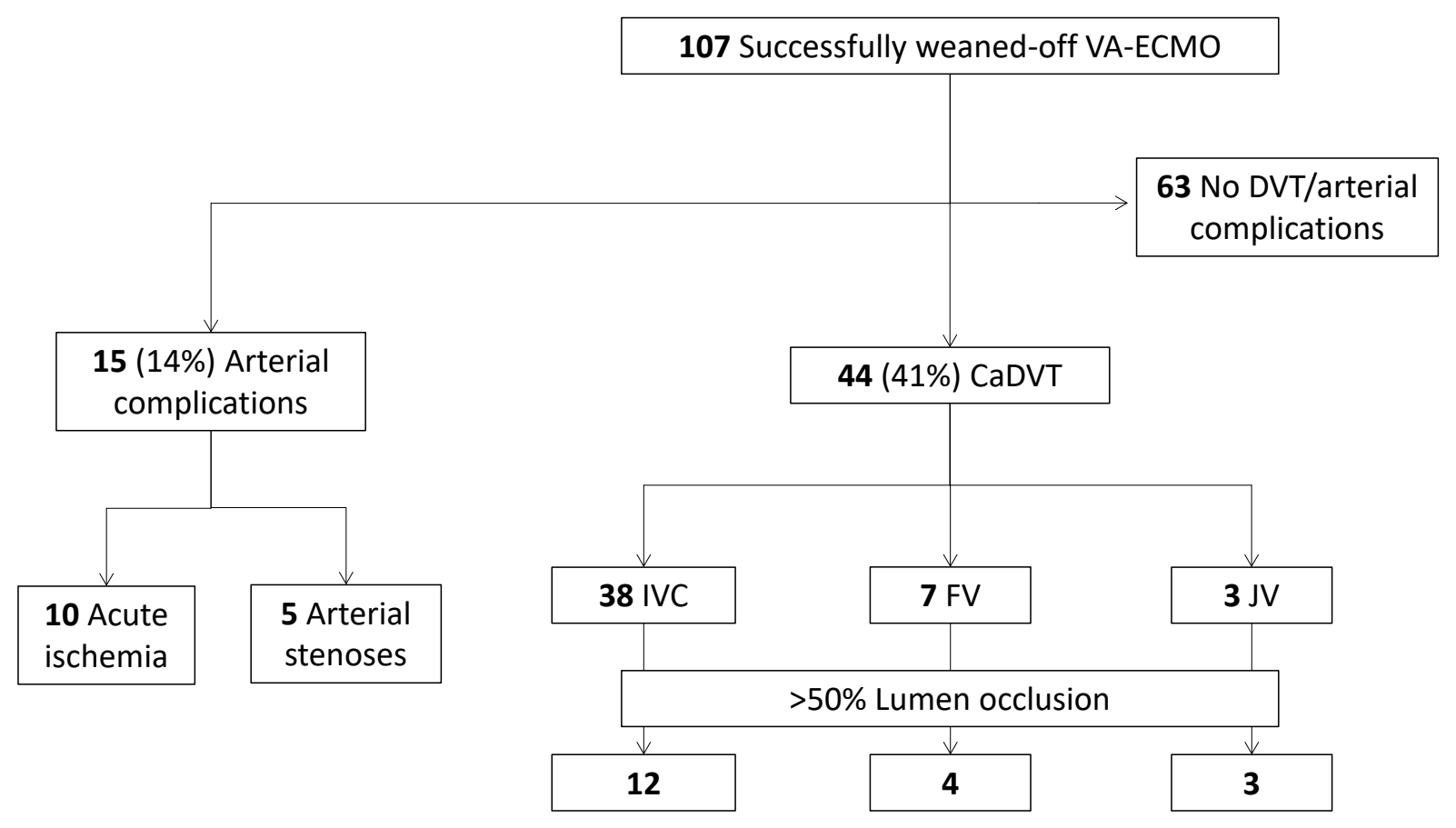




\section{References}

1. Pineton de Chambrun M, Bréchot N, Combes A: Venoarterial extracorporeal membrane oxygenation in cardiogenic shock: indications, mode of operation, and current evidence. Curr Opinion Crit Care 2019; 25:397-402

2. Doyle AJ, Hunt BJ: Current Understanding of How Extracorporeal Membrane Oxygenators Activate Haemostasis and Other Blood Components. Front Med 2018; 5:352

3. Hirsch DR, Ingenito EP, Goldhaber SZ: Prevalence of deep venous thrombosis among patients in medical intensive care. JAMA 1995; 274:335-7

4. Luyt C-E, Bréchot N, Demondion P, Jovanovic T, Hékimian G, Lebreton G, Nieszkowska A, Schmidt M, Trouillet J-L, Leprince P, Chastre J, Combes A: Brain injury during venovenous extracorporeal membrane oxygenation. Intensive Care Med 2016; 42:897907

5. Shafii AE, Brown CR, Murthy SC, Mason DP: High incidence of upper-extremity deep vein thrombosis with dual-lumen venovenous extracorporeal membrane oxygenation. J Thorac Cardiovasc Surg 2012; 144:988-9

6. Trudzinski FC, Minko P, Rapp D, Fähndrich S, Haake H, Haab M, Bohle RM, Flaig M, Kaestner F, Bals R, Wilkens H, Muellenbach RM, Link A, Groesdonk HV, Lensch C, Langer F, Lepper PM: Runtime and aPTT predict venous thrombosis and thromboembolism in patients on extracorporeal membrane oxygenation: a retrospective analysis. Ann Intens Care 2016; 6 
7. Cooper E, Burns J, Retter A, Salt G, Camporota L, Meadows CIS, Langrish CCJ, Wyncoll D, Glover G, Ioannou N, Daly K, Barrett NA: Prevalence of Venous Thrombosis Following Venovenous Extracorporeal Membrane Oxygenation in Patients With Severe Respiratory Failure: Crit Care Med 2015; 43:e581-4

8. Fisser C, Reichenbächer C, Müller T, Schneckenpointner R, Malfertheiner MV, Philipp A, Foltan M, Lunz D, Zeman F, Lubnow M: Incidence and Risk Factors for CannulaRelated Venous Thrombosis After Venovenous Extracorporeal Membrane Oxygenation in Adult Patients With Acute Respiratory Failure: Crit Care Med 2019; 47:e332-9

9. Parzy G, Daviet F, Persico N, Rambaud R, Scemama U, Adda M, Guervilly C, Hraiech S, Chaumoitre K, Roch A, Papazian L, Forel J-M: Prevalence and Risk Factors for Thrombotic Complications Following Venovenous Extracorporeal Membrane Oxygenation: A CT Scan Study. Crit Care Med 2020; 48:192-9

10. Abrams D, Combes A, Brodie D: Extracorporeal membrane oxygenation in cardiopulmonary disease in adults. J Am Coll Cardiol 2014; 63:2769-78

11. Danial P, Hajage D, Nguyen LS, Mastroianni C, Demondion P, Schmidt M, Bouglé A, Amour J, Leprince P, Combes A, Lebreton G: Percutaneous versus surgical femorofemoral veno-arterial ECMO: a propensity score matched study. Intensive Care Med $2018 ; 44: 2153-61$

12. Chambrun MP de, Bréchot N, Lebreton G, Schmidt M, Hekimian G, Demondion P, Trouillet J-L, Leprince P, Chastre J, Combes A, Luyt C-E: Venoarterial extracorporeal membrane oxygenation for refractory cardiogenic shock post-cardiac arrest. Intensive Care Med 2016; 42:1999-2007 
13. Aissaoui N, Luyt C-E, Leprince P, Trouillet J-L, Léger P, Pavie A, Diebold B, Chastre J, Combes A: Predictors of successful extracorporeal membrane oxygenation (ECMO) weaning after assistance for refractory cardiogenic shock. Intensive Care Med 2011; $37: 1738-45$

14. Minet C, Potton L, Bonadona A, Hamidfar-Roy R, Somohano CA, Lugosi M, Cartier J-C, Ferretti G, Schwebel C, Timsit J-F: Venous thromboembolism in the ICU: main characteristics, diagnosis and thromboprophylaxis. Crit Care 2015; 19:287

15. Jackson SP, Darbousset R, Schoenwaelder SM: Thromboinflammation: challenges of therapeutically targeting coagulation and other host defense mechanisms. Blood 2019; $133: 906-18$

16. Whitlock RP, Sun JC, Fremes SE, Rubens FD, Teoh KH: Antithrombotic and Thrombolytic Therapy for Valvular Disease. Chest 2012; 141:e576S-e600S

17. Thomas J, Kostousov V, Teruya J: Bleeding and Thrombotic Complications in the Use of Extracorporeal Membrane Oxygenation. Semin Thromb Hemost 2018; 44:020-9

18. Bates SM, Jaeschke R, Stevens SM, Goodacre S, Wells PS, Stevenson MD, Kearon C, Schunemann HJ, Crowther M, Pauker SG, Makdissi R, Guyatt GH: Diagnosis of DVT. Chest 2012; 141:e351S-e418S

19. Mazzeffi M, Strauss E, Meyer M, Hasan S, Judd M, Abuelkasem E, Chow J, Nandwani V, McCarthy P, Tanaka K: Coagulation Factor Levels and Underlying Thrombin Generation Patterns in Adult Extracorporeal Membrane Oxygenation Patients. Anesth Analg 2019; 129:659-66 
20. Panigada M, Cucino A, Spinelli E, Occhipinti G, Panarello G, Novembrino C, Consonni D, Protti A, Lissoni A, Arcadipane A, Pesenti A, Grasselli G: A Randomized Controlled Trial of Antithrombin Supplementation During Extracorporeal Membrane Oxygenation. Crit Care Med 2020; 48:1636-44

21. Rastan AJ, Lachmann N, Walther T, Doll N, Gradistanac T, Gommert JF, Lehmann S, Wittekind C, Mohr FW: Autopsy Findings in Patients on Postcardiotomy Extracorporeal Membrane Oxygenation (ECMO). Inter J Artif Organs 2006; 29:1121-31 